\title{
РЭМ-анализ свойств поверхности экспериментальных сульфокатионообменных мембран Ralex
}

\author{
Акберова Э.М., Васильева В.И., Костылев Д.В., Смагин М.А. \\ ФГБОУ ВО «Воронежский государственный университет», Воронеж
}

Поступила в редакцию 15.09.2019 г.

DOI: 10.17308/sorpchrom.2019.19/1170

\begin{abstract}
Проведен сравнительный анализ влияния технологии изготовления гетерогенных сульфокатионитовых мембран Ralex CM Pes производства «MEGA» a.s. (Чехия) на структурные свойства их поверхности методом РЭМ. При изготовлении экспериментальных мембран варьировались размеры частиц ионообменника при постоянном объемном соотношении катионита и полиэтилена. Размер частиц сульфокатионообменника изменялся путем использования разного времени его измельчения. С увеличением времени измельчения ионообменника от 5 до 80 мин структура поверхности мембраны становится более однородной вследствие уменьшения размеров частиц ионообменников и расстояния между ними, а также уменьшения доли и размеров дефектов структур. Выявлено уменьшение размеров частиц ионообменников и расстояния между ними более чем в 1.5 раза. Значительно возрастает доля ионообменника с радиусом менее 1 мкм. При этом наблюдается уменьшение доли, а также размеров пор и дефектов структуры в 1.5 раза. Соотношение долей проводящей и непроводящей фаз на поверхности мембраны остается практически постоянным.
\end{abstract}

Ключевые слова: растровая электронная микроскопия, гетерогенная ионообменная мембрана, неоднородность поверхности.

\section{SEM-analysis of surface properties of experimental sulfocation-exchange membranes Ralex}

\author{
Akberova E.M., Vasil'eva V.I., Kostylev D.V., Smagin M.A. \\ Voronezh State University, Voronezh
}

A comparative analysis of the effect of the manufacturing technology of heterogeneous sulfocationexchange membranes Ralex CM Pes produced by MEGA a.s. (Czech Republic) on the structural properties of their surface by SEM was carried out. The CM Pes membrane is a composite of a sulfocation-exchanger with polyethylene and reinforcing polyester fiber. In the manufacture of experimental membranes, the particle sizes of the ion-exchanger differed at a constant volume ratio of cation-exchange resin and polyethylene. The resin particle sizes were varied by using different milling time. The study of the surface of swollen membrane samples was performed by scanning electron microscopy in the low-vacuum mode. Quantitative assessment of the fraction of ion-exchange material and porosity on the membrane surface was carried out using the authors' software package.

With an increase in the milling time of the ion-exchanger from 5 to $80 \mathrm{~min}$, the structure of the membrane surface becomes more homogeneous due to a decrease in the resin particle sizes and the distance between them, as well as a decrease in the fraction and size of structure defects. A more than 1.5 -fold decrease in the size of ion-exchanger particles and in the distance between them was revealed. The fraction of the ion-exchanger with a radius of less than $1 \mu \mathrm{m}$ increases significantly. At the same time, there is a 1.5 -fold decrease in the fraction, as well as in the size of pores and structure defects. The ratio of the fractions of the conducting and nonconducting phases on the membrane surface remains almost constant (15-17\%). mogeneity.

Keywords: scanning electron microscopy, heterogeneous ion-exchange membrane, surface inho- 


\section{Введение}

Важную роль в электрохимическом поведении гетерогенных ионообменных мембран играет электрическая неоднородность их поверхности, заключающаяся в наличии участков с высокой (фаза ионообменника) и низкой (фаза полиэтилена) проводимостью. В работах [1-8] показана возможность интенсификации массопереноса в электромембранной системе путем совершенствования морфологии поверхности ионообменных мембран. Использование мембран с оптимизированной морфологией поверхности в процессе электродиализа для обессоливания и деионизации природных вод и технологических растворов создает предпосылки для существенного повышения эффективности этих процессов в предельных и сверхпредельных токовых режимах.

Объективную информацию о морфологии поверхности мембран дают методы визуализации: сканирующая электронная $[1,2,9-14]$, сканирующая силовая $[9,11$, $15]$ и оптическая $[16,17]$ микроскопия. Метод РЭМ с энергодисперсионным рентгеновским анализом является полезным инструментом для качественного и полуколичественного анализа элементного состава поверхности или сечения мембран различного типа и в зависимости от условий эксплуатации [10, 16, 18-20].

Ионообменные мембраны работоспособны только в набухшем состоянии. Однако традиционно применяемые методы атомно-силовой микроскопии и высоковакуумного варианта растровой электронной микроскопии позволяют исследовать образцы только в сухом состоянии. Применение оптической микроскопии для изучения набухших мембран осложняется близкой светопроводимостью ионита и полиэтилена, что негативно влияет на точность определения размера проводящих и непроводящих участков [21]. В работах [2, 22] предложен и апробирован способ определения доли ионопроводящей и инертной фаз на поверхности набухших гетерогенных мембран на основании РЭМ-результатов, полученных при сканировании сухих образцов. Выражение для пересчета доли проводящей поверхности сухой мембраны на набухший образец получено при предположении, что увеличение линейных размеров мембран в процессе набухания происходит, в основном, за счет увеличения размеров ионообменного материала. Прямую визуализацию структуры поверхности ионообменных мембран разного типа в набухшем состоянии позволяет проводить низковакуумный вариант РЭМ [7, 12, $23,24]$.

Целью работы явилась экспериментальная оценка методом РЭМ влияния технологии изготовления гетерогенных сульфокатионообменных мембран Ralex CM Pes на структурные свойства их поверхности.

\section{Эксперимент}

Объекты исследования. Объектами исследования были выбраны экспериментальные образцы гетерогенных сульфокатионообменных мембран Ralex CM Pes («MEGA» a.s., Чехия). Мембрана CM Реs является композитом сульфокатионообменника с полиэтиленом и армирующей тканью полиэстер [25]. Экспериментальные образцы мембран получены вальцеванием гомогенизированной смеси измельченного ионообменника различного размера с полиэтиленом. Размер частиц сульфокатионообменника варьировался путем использования разного времени его измельчения от 5 до 80 мин. Объемная доля ионообменной смолы в смеси, используемой при изготовлении мембран CM Pes, составляла $58 \%$. 
Все образцы исследуемых мембран подвергали стандартной солевой предподготовке [26] путем выдерживания в насыщенном растворе $\mathrm{NaCl}$, затем последовательно в растворах $\mathrm{NaCl}$ с концентрацией 100 и 30 г/дм³

Растровая электронная микроскопия. Исследования морфологии поверхности мембран проводили методом растровой электронной микроскопии (РЭМ) с применением микроскопа марки JSM-6380 LV (Япония). В камере с исследуемым образцом было регулируемое давление, что позволило исследовать в низковакуумном режиме мембраны в рабочем (набухшем) состоянии $[12,23]$. Электронномикроскопическая съемка образцов проводилась в низковакуумном режиме с использованием отраженных электронов при ускоряющем напряжении 20 кВ. Предварительная подготовка образцов мембран не проводилась, так как основным преимуществом низковакуумных приборов является нейтрализация поверхностного заряда положительно заряженными атомами газа, что делало покрытие проводящим слоем ненужным [27]. Основным фактором, влияющим на количество отраженных электронов, является элементный состав области детектирования [28]. Поэтому области анализируемой поверхности, содержащие атомы с более высоким порядковым номером, соответствуют светлым участкам на изображении вследствие более интенсивного отражения электронов. Таким образом, участкам ионообменника, ионогенные группы которого содержат атомы серы, кислорода, натрия отвечают области светлосерого цвета. Полиэтилену, в составе которого атомы углерода, соответствует темносерый цвет. Темная граница между ними свидетельствует о наличие поры или дефекта структуры.

Программное обеспечение. Количественная оценка доли ионообменного материала и пористости на поверхности мембран проводилась с помощью авторского программного комплекса. Программный комплекс представляет собой приложение, разработанное на языке Delphi $[29,30]$. Приложение обеспечивает автоматизацию анализа морфологии поверхности и сечения ионообменных мембран посредством цифровой обработки РЭМ-изображений. Программный комплекс предоставляет широкий спектр возможностей по цифровой обработке изображений: а) с целью шумоподавления предложены различные виды фильтров (медианный и усредняющий); б) выделение перепадов яркости реализовано с помощью градиента Собела, Робертса, а также Лапласиана, в) бинаризация изображения осуществляется посредством глобального или локального порога. Для оценки относительной доли микрофаз на поверхности мембраны использован метод выращивания областей. Помимо этого в программный комплекс включен дополнительный модуль построения гистограммы распределения проводящих участков поверхности по эффективным радиусам.

В предварительных экспериментах для одновременного определения доли и размера микрофаз с учетом «размерного эффекта» неоднородной поверхности гетерогенных ионообменных мембран была выбрана оптимальная величина относительной кратности увеличения - 500. Долю ионообменника на поверхности гетерогенных мембран определяли по формуле $S=\left(\Sigma S_{i} / S\right) \cdot 100 \%$, где $\Sigma S_{i}-$ суммарная площадь ионообменных участков, $S$ - площадь сканируемого участка. Под радиусом ионообменного участка $R$ понимали эффективный радиус моделируемого программой участка круглой формы по площади эквивалентного реальной площади ионообменника произвольной формы. При вычислении среднего радиуса ионообменника брали средневзвешенное значение [12], учитывающее различную долю участков с отличающимися размерами.

Долю $P$ и средневзвешенное значение радиуса пор $\bar{r}$ на поверхности мембран рассчитывали аналогичным образом. Под понятием «пора» принималось пространство между ионообменником и инертным связующим (полиэтиленом). В качестве 
пор были учтены также трещины на полиэтилене, которые образовались в результате деструкции полимеров при изготовлении мембран, в связи с тем, что они могут иметь сквозной характер.

Статистический анализ. Обработка результатов измерений проводилась методами математической статистики [31]. Величины средних результатов измерений $\bar{x}$, дисперсии $V^{2}$ и стандартные отклонения $V_{\bar{x}}$ и $V_{r}$ находили с использованием приемов статистики малых выборок. Величину доверительного интервала средних результатов измерений $\Delta x$ находили с использованием $t$-критерия (коэффициент Стьюдента) для уровня значимости $\alpha=1-P$ при доверительной вероятности $P=0.95$.

При определении характеристик поверхности гетерогенных ионообменных мембран с использованием метода сканирующей электронной микроскопии различные части поверхности каждого образца мембраны сканировали 8-10 раз. Обработку каждой фотографии производили 2-3 раза.

\section{Обсуждение результатов}

Структура поверхности исследуемых гетерогенных ионообменных мембран Ralex является неоднородной (рис. 1). Визуализируются светлые участки проводящей электрический ток поверхности (частицы ионообменника) и темные участки инертного полиэтилена, соответствующие непроводящей поверхности. При этом значительная часть поверхности мембран экранирована полиэтиленом, а токопроводящая фаза, в которой локализованы ионогенные группы, занимает меньшую долю. Видно, что проводящие участки на поверхности гетерогенных мембран CM Pes pacположены хаотично.

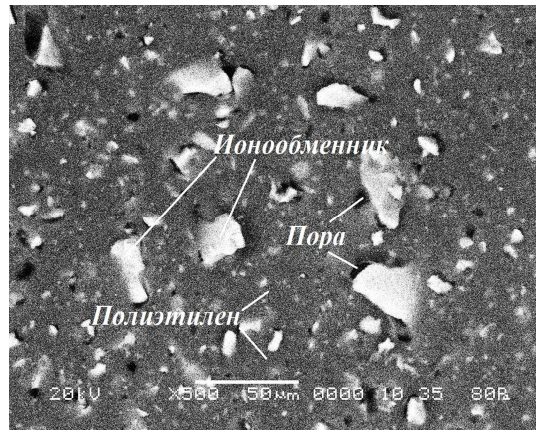

a

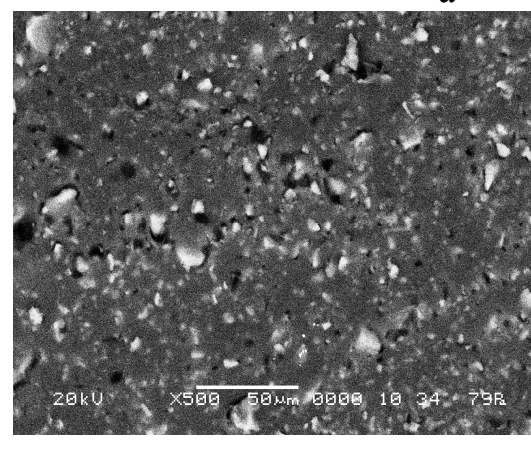

B

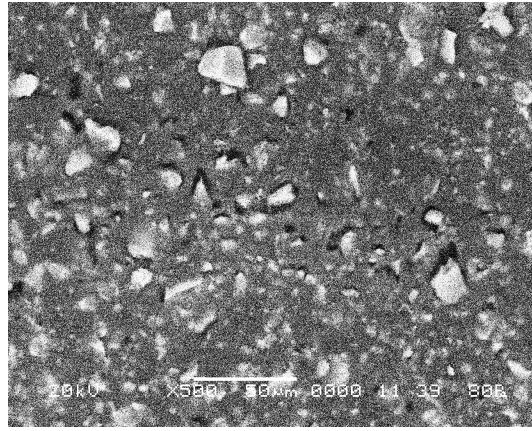

б

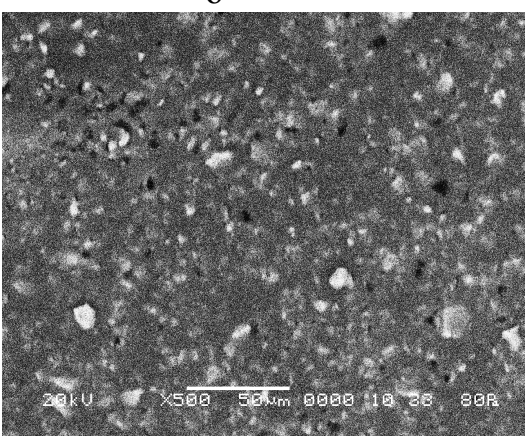

$\Gamma$

Рис. 1. РЭМ-изображения поверхности набухших образцов сульфокатионообменных мембран СМ Реs при увеличении 500. Время измельчения ионообменника: 5 (а), 40 (б), 60 (в) и 80 (г) мин

Установлено, что с увеличением времени измельчения ионита соотношение проводящей и непроводящей фаз на поверхности экспериментальных мембран Ralex 
сохраняется постоянным. Доля ионообменника на поверхности мембран в набухшем состоянии составляет 15-17\%. Ранее [32, 33] установлено, что доля проводящей поверхности серийно выпускаемых «MEGA» a.s. мембран Ralex в набухшем состоянии составляет $25-30 \%$.

Анализ распределения ионообменных участков по радиусам показывает, что радиусы ионообменных участков мембраны CM Pes c ионообменником после 5 мин измельчения находятся в диапазоне 0.6-15 мкм (рис. 2). С ростом времени измельчения ионообменных частиц установлено увеличение на поверхности их общего количества и значительное возрастание доли ионообменника с радиусом менее 1 мкм. Однако максимум на кривой распределения для образцов мембран Ralex CM Pes ocтается постоянным и находится в области 1-2 мкм. Согласно оценкам, проведенным в работе [32], характерный радиус проводящих участков на поверхности серийновыпускаемых компанией «MEGA» a.s. набухших образцов катионообменных мембран CM Pes варьируется в диапазоне от 0.5 до 7 мкм. Похожие результаты получены методом РЭМ для сухих образцов мембраны при увеличении 200 в работе [34]: анализ РЭМ-изображений образца мембраны Ralex CM показал, что размер проводящих полимерных гранул варьируется в диапазоне от единиц до десятков микрометров.

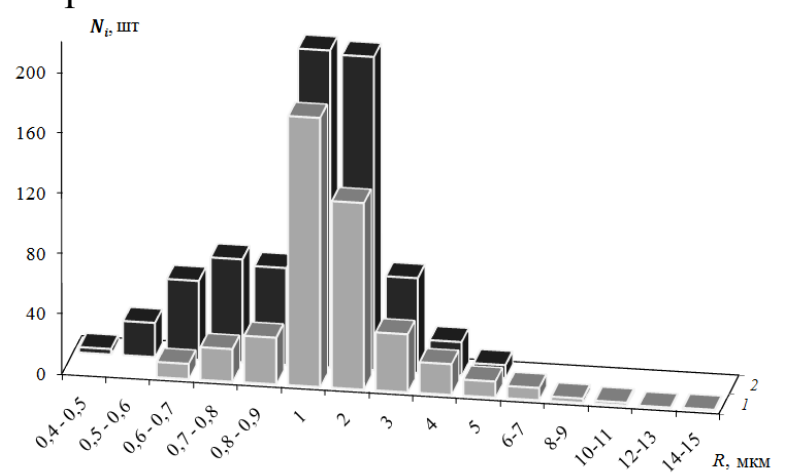

a

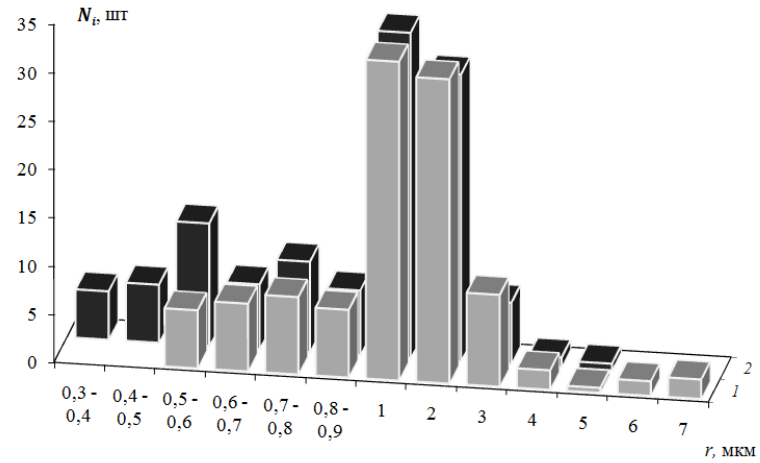

6

Рис. 2. Распределение ионообменных участков (а) и макропор (б) по радиусам на поверхности набухших образцов гетерогенных мембран CM Pes при времени измельчения ионообменника 5 (1) и 80 (2) мин

Увеличение продолжительности измельчения ионообменника соответствует уменьшению величины средневзвешенного радиуса $\bar{R}$ ионообменных частиц на поверхности набухших образцов мембран CM Pes на 20\%(рис. 3).

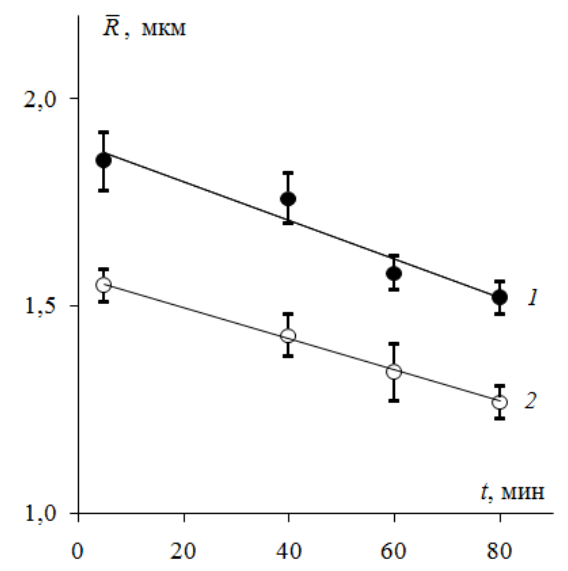

Рис. 3. Средневзвешенный радиус ионообменных участков (1) и макропор (2) на поверхности гетерогенных мембран Ralex CMH Pes с различным временем измельчения ионообменника 
Для мембран с ионообменником после 80 мин измельчения $\bar{R}=1.52 \pm 0.03$ мкм. Известно [32], что значение средневзвешенного радиуса для серийно выпускаемой сульфокатионообменной мембраны Ralex составляет $\bar{R}=1.88$ мкм.

$\mathrm{C}$ ростом времени измельчения уменьшение размеров ионопроводящих участков на поверхности экспериментальных мембран Ralex сопровождается сближением зон проводящей поверхности: для времени измельчения 5 и 80 мин эффективное расстояние между ионообменниками уменьшается более чем в полтора раза и составляет $9.3 \pm 0.8$ и $5.5 \pm 0.4$ мкм, соответственно.

Уменьшение размеров ионопроводящих участков на поверхности экспериментальных мембран Ralex сопровождается уменьшением доли макропор и дефектов структуры в 1.5 раза. С ростом продолжительности измельчения ионообменных частиц установлено значительное возрастание доли макропор с радиусом менее 0.5-0.6 мкм (рис. 2б). При этом средневзвешенные величины радиусов макропор составляют $1.55 \pm 0.03$ и $1.27 \pm 0.04$ мкм для мембран с ионообменником после 5 и 80 мин измельчения, соответственно (рис. 3).

\section{Заключение}

Методом РЭМ выявлены значительные различия свойств поверхности гетерогенных сульфокатионообменных мембран Ralex при изменении технологии их изготовления. Установлено, что структура поверхности мембран становится электрически более однородной с увеличением времени измельчения ионообменника (уменьшением размера частиц). Увеличение времени измельчения частиц ионообменника от 5 до 80 мин. при производстве мембран приводит к уменьшению размеров и сближению зон проводящей ток ионообменной фазы. С увеличением времени измельчения частиц ионообменника также уменьшаются доля и размеры макропор и дефектов структуры. При этом соотношение долей проводящей и непроводящей фаз на поверхности остается практически постоянным и составляет 15-17\%.

\section{Работа выполнена при поддержке гранта Президента Российской Федерации MK-925.2018.3. \\ Авторы выражают благодарность компании «Меgа» а.s. (Чешская Республика) и г-ну Новаку Л. за предоставленные экспериментальные мембраны Ralex CM Pes. Микрофотографии поверхности мембран получены на оборудовании Центра коллективного пользования Воронежского государственного университета. URL: http://ckp.vsu.ru.}

\section{Список литературы}

1. Balster J., Yildirim M.H., Stamatialis D.F., Ibanez R. et al. // J. Phys. Chem. B. 2007. Vol. 111. pp. 2152-2165. DOI: $10.1021 /$ jp068474t

2. De Valenca J.C., Wagterveld R.M., Lammertink R.G.H., Tsai P.A. // Phys. Rev. E. 2015. Vol. 92. Art. no 031003. DOI: 10.1103/PhysRevE.92.031003

3. Wessling M., Morcillo L.G., Abdu S. // Sci. Reports. 2014. Vol. 4. p. 4294. DOI:10.1038/srep04294

4. Tadimeti J. G. D., Kurian V., Chandra A., Chattopadhyay S. // J. Membr. Sci. 2016. Vol.
499. pp. 418-428. DOI: 10.1016/j.memsci.2015 11.001

5. Заболоцкий В.И., Новак Л., Коваленко А.В., Никоненко В.В. и др. // Мембраны и мембранные технологии. 2017. Т. 7. № 4. С. 265-276.

6. Никоненко В.В., Мареев С.А., Письменская Н.Д., Узденова А.М. и др. // Электрохимия. 2017. Т. 53. № 10. С. 1266-1289.

7. Васильева В.И., Акберова Э.М., Заболоцкий В.И. // Электрохимия. 2017. Т. 53. № 4. С. 452-465. 
8. Akberova E.M., Vasil'eva V.I., Zabolotsky V.I., Novak L. // J. Membr. Sci. 2018. Vol. 566. pp. 317-328. DOI: 10.1016/j.memsci.2018. 08.042

9. Kamusewitz, H., Schossig-Tiedemann M., Keller M., Paul D. // Surf. Sci. 1997. Vol. 377379. pp. 1076-1081. DOI: 10.1016/S00396028(96)01549-X

10.Ghalloussi R., Garcia-Vasquez W., Chaabane L., Dammak L. et al. // J. Membr. Sci. 2013. Vol. 436. pp. 68-78. DOI: 10.1016/ j.memsci.2013.02.011

11.Васильева В. И., Кранина Н. А., Малыхин М. Д., Акберова Э.М. и др. // Поверхность. Рентгеновские, синхротронные и нейтронные исследования. 2013. № 2. С. 5161.

12.Васильева В.И., Акберова Э.М., Жильцова А.В., Черных Е.И. и др. // Поверхность. Рентгеновские, синхротронные и нейтронные исследования. 2013. № 9. С. 27-34.

13.Martí-Calatayud M.C., Buzzi D.C., GarcíaGabaldón M., Bernardes A.M. et al. // $J$. Membr. Sci. 2014. Vol. 466. pp. 45-57. DOI: 10.1016/j.memsci.2014.04.033

14. Asraf-Snir M., Gilron J., Oren Y. // J. Membr. Sci. 2016. Vol. 520. pp. 176-186. DOI: 10.1016/j.memsci.2016.07.013

15.Lehmani A., Durand-Vidal S., Turq P. // J. Appl. Polym. Sci. 1998. Vol. 68. pp. 503-508. DOI: $10.1002 /($ SICI)1097-4628(19980418)68:3 $<503:$ :AID-APP16>3.0.CO;2-V

16. Araya-Farias M., Bazinet L. // J. Colloid Interface Sci. 2006. Vol. 296. pp. 242-247. DOI: 10.1016/j.jcis.2005.08.040

17.Pismenskaya N.D., Pokhidnia E.V., Pourcelly G. \& Nikonenko, V.V. // J. Memb. Sci. 2018. Vol. 566. pp. 54-68. DOI: 10.1016/j.memsci.2018.08.055

18.Васильева В.И., Акберова Э.М., Голева Е.А., Яцев А.М. и др. // Поверхность. Рентгеновские, синхротронные и нейтронные исследования. 2017. № 4. С. 49-56.

19.Zhao Zh., Shia Sh., Cao H., Shan B. et. al. // Desalination. 2018. Vol. 428. pp. 199-206. DOI: 10.1016/j.desal.2017.11.021

20.Belashova E., Mikhaylin S., Pismenskaya N., Nikonenko V. et. al. // Sep. Purif. Techn. 2017. Vol. 189. pp. 441-448. DOI: 10.1016/j.seppur.2017.08.045

21.Бутыльский Д.Ю., Мареев С.А., Никоненко В.В., Письменская Н.Д. и др. // Мембраны и мембранные технологии. Т.6. №. 4. C. 351-358.
22.Volodina E., Pismenskaya N., Nikonenko V., Larchet C. et. al. // J. Colloid Interface Sci. 2005. Vol. 285. pp. 247-258. DOI: 10.1016/j.jcis.2004.11.017

23.Васильева В. И., Письменская Н. Д., Акберова Э. М., Небавская К. А. // Журн. физ. химии. 2014. Т. 88. № 8. С. 1114-1120.

24.Васильева В.И., Акберова Э.М., Шапошник В.А., Малыхин М.Д. // Электрохимия. 2014. Т. 50. № 8. С. 875-883.

25.Сайт MEGA a.s. Режим доступа: https://www.mega.cz/membranes/ (дата обращения 20.09.2019)

26.Березина Н.П., Кононенко Н.А., Дворкина Г.А, Шельдешов Н.В. Физикохимические свойства ионообменных материалов. Краснодар: Изд-во Кубан. гос. ун-та, 1999. 82 c.

27.Рид С.Дж.Б. Электронно-зондовый микроанализ и растровая электронная микроскопия в геологии. Москва: Техносфера. 2008. $232 \mathrm{c}$.

28. Углов В.В., Коваль Н.Н., Кулешов А.К., Иванов Ю.Ф. и др. // Поверхность. Рентгеновские, синхротронные и нейтронные исследования. 2011. №4. С. 50-58.

29.Сирота Е.А., Кранина Н.А., Васильева В.И., Малыхин М.Д. и др. // Вестн. Воронеж. гос. ун-та. Сер. Химия. Биология. Фармация. 2011. № 2. С. 53-59.

30 .Оценка поверхностной и объемной неоднородности гетерогенных ионообменных мембран по электронно-микроскопическим снимкам : свид-во о гос. регистрации программы для ЭВМ / Е.А. Сирота, В.И. Васильева, Э.М. Акберова ; ФГБОУ ВПО ВГУ. № $2012617310 \quad 29.08 .2012 ;$ зарегистр. 26.10.2012. 2 c.

31.Тейлор Дж. Введение в теорию ошибок / Пер. с англ. канд. физ.-мат. наук Л.Г. Деденко. Москва: Мир. 1985. 272 с.

32.Васильева В. И., Жильцова А. В., Акберова Э. М., Фатаева А. И. // Конденсированные среды и межфазные гранищьы. 2014. Т. 16. № 3. C. 257-261.

33.Melnikov S., Loza S., Sharafan M., Zabolotskiy V. // Separ. Purif. Technol. 2015. Vol. $157 . \quad$ pp. 179-191. DOI: 10.1016/j.seppur.2015.11.025

34.Svoboda M., Slouka Z., Schrott W., Šnita D. // Microelectronic Engineering. 2009. Vol. 86. pp. 1371-1374. DOI: 10.1016/j.mee.2009.01.019 


\section{References}

1. Balster J., Yildirim M.H., Stamatialis D.F., Ibanez R. et al., J. Phys. Chem. B, 2007, Vol. 111, pp. 2152-2165. DOI: $10.1021 /$ jp068474t

2. De Valenca J.C., Wagterveld R.M., Lammertink R.G.H., Tsai P.A., Phys. Rev. E, 2015, Vol. 92, Art. no 031003. DOI: 10.1103/PhysRevE.92.031003

3. Wessling M., Morcillo L.G., Abdu S., Sci. Reports, 2014, Vol. 4, p. 4294. DOI:10.1038/srep04294

4. Tadimeti J. G. D., Kurian V., Chandra A., Chattopadhyay S., J. Membr. Sci., 2016, Vol. 499, pp. 418-428. DOI:

10.1016/j.memsci.2015.11.001

5. Zabolotsky V.I., Novak L., Kovalenko A.V., Nikonenko V.V. et al., Petroleum Chem., 2017, Vol. 57, pp. 779-789. DOI: 10.1134/S0965544117090109

6. Nikonenko V.V., Mareev S.A., Pis'menskaya N.D., Uzdenova A.M. et al., Russ. J. Electrochem., 2017, Vol. 53, pp. 11221144. DOI: $10.1134 / \mathrm{S} 1023193517090099$

7. Vasil'eva V.I., Akberova E.M., Zabolotskii V.I., Russ. J. Electrochem., 2017, Vol. 53, pp. 398-410. DOI: 10.1134/S1023193517040127

8. Akberova E.M., Vasil'eva V.I., Zabolotsky V.I., Novak L., J. Membr. Sci., 2018, Vol. 566, pp. 317-328.

DOI:

10.1016/j.memsci.2018.08.042

9. Kamusewitz, H., Schossig-Tiedemann M., Keller M., Paul D., Surf. Sci., 1997, Vol. 377379 , pp. 1076-1081. DOI: 10.1016/S00396028(96)01549-X

10.Ghalloussi R., Garcia-Vasquez W., Chaabane L., Dammak L. et al., J. Membr. Sci., 2013, Vol. 436, pp. 68-78. DOI: 10.1016/j.memsci.2013.02.011

11.Vasil'eva V.I., Kranina N.A., Malykhin M.D., Akberova E.M. et al., J. Surf. Investigation. X-ray, Synchrotron and Neutron Techniques, 2013, Vol. 7, pp. 144-153. DOI: $10.1134 / \mathrm{S} 1027451013010321$

12.Vasil'eva V.I., Akberova E.M., Zhiltsova A.V., Chernykh E.I. et al., J. Surf. Investigation. $X$-ray, Synchrotron and Neutron Techniques, 2013, Vol. 7, pp. 833-840. DOI: 10.1134/S1027451013050194

13.Martí-Calatayud M.C., Buzzi D.C., GarcíaGabaldón M., Bernardes A.M. et al., J. Membr. Sci., 2014, Vol. 466, pp. 45-57. DOI: 10.1016/j.memsci.2014.04.033
14. Asraf-Snir M., Gilron J., Oren Y., J. Membr. Sci., 2016, Vol. 520, pp. 176-186. DOI: 10.1016/j.memsci.2016.07.013

15.Lehmani A., Durand-Vidal S., Turq P., $J$. Appl. Polym. Sci., 1998, Vol. 68, pp. 503-508. DOI: $10.1002 /($ SICI) $1097-$ 4628(19980418)68:3<503::AID-

APP16>3.0.CO;2-V

16. Araya-Farias M., Bazinet L., J. Colloid Interface Sci., 2006, Vol. 296, pp. 242-247. DOI: 10.1016/j.jcis.2005.08.040

17.Pismenskaya N.D., Pokhidnia E.V., Pourcelly G. \& Nikonenko, V.V., J. Memb. Sci., 2018, Vol. 566, pp. 54-68. DOI: 10.1016/j.memsci.2018.08.055

18.Vasil'eva V.I., Akberova E.M., Goleva E.A., Yatsev A.M. et al., J. Surf. Investigation. $X$-ray, Synchrotron and Neutron Techniques, 2017, Vol. 11, No 2, pp. 49-56. DOI: $10.1134 / \mathrm{S} 1027451017020367$

19.Zhao Zh., Shia Sh., Cao H., Shan B. et. al., Desalination, 2018, Vol. 428, pp. 199-206. DOI: 10.1016/j.desal.2017.11.021

20.Belashova E., Mikhaylin S., Pismenskaya N., Nikonenko V. et. al., Sep. Purif. Techn., 2017, Vol. 189, pp. 441-448. DOI: 10.1016/j.seppur.2017.08.045

21.Butylskii, D.Y., Mareev, S.A., Nikonenko, V.V., Pismenskaya, N.D. et. al., Petroleum Chem., Vol. 56, pp. 1006-1013. DOI: 10.1134/S0965544116110037

22.Volodina E., Pismenskaya N., Nikonenko V., Larchet C. et. al., J. Colloid Interface Sci., 2005, Vol. 285, pp. 247-258. DOI: 10.1016/j.jcis.2004.11.017

23. Vasil'eva V. I., Pismenskaya N. D., Akberova E. M., Nebavskaya K. A., Russ. J. Phys. Chem. A, 2014, Vol. 88, No. 8, pp. 1293-1299. DOI: $10.1134 / \mathrm{S} 0036024414080317$

24.Vasil'eva V.I., Akberova E.M., Shaposhnik V.A., Malykhin M.D., Russ. J. Electrochem, 2014, Vol. 50, pp. 789-797. DOI: 10.1134/S102319351408014X

25. Website of MEGA a.s. Available at: https://www.mega.cz/membranes/ (accessed 20.09.2019)

26.Berezina N.P., Kononenko N.A., Dvorkina G.A, Shel'deshov N.V. Fiziko-khimicheskiye svoystva ionoobmennykh materialov. Krasnodar, Izd-vo Kuban. gos. un-ta, 1999, 82 p. 
27.Reed S. J. B. Electron Microprobe Analysis and Scanning Electron Microscopy in Geology. Cambridge, UK: Cambridge University Press. 2005. 212 p.

28.Uglov V. V., Koval' N. N., Kuleshov A. K., Ivanov Yu. F. et. al., J. Surf. Investigation. $X$-ray, Synchrotron and Neutron Techniques, 2011, No 5, pp. 350-357. DOI: $10.1134 / \mathrm{S} 1027451011040173$

29. Sirota E.A., Kranina N.A., Vasil'eva V.I., Malykhin M.D. et al., Vestn. Voronezh. gos. unta. Ser. Khimiya. Biologiya. Farmatsiya, 2011, № 2, pp. 53-59.

30. Otsenka poverkhnostnoy i obyemnoy neodnorodnosti geterogennykh ionoobmennykh membran po elektronno-mikroskopicheskim snimkam: certificate of state registration of a computer program / E.A. Sirota, V.I. Vasil'eva,

Акберова Эльмара Маликовна - к.х.н., ведущий инженер кафедры аналитической химии, Воронежский государственный университет, Воронеж.

Васильева Вера Ивановна - д.х.н., профессор кафедры аналитической химии, Воронежский государственный университет, Воронеж

Костылев Денис Викторович - студент химического факультета, Воронежский государственный университет, Воронеж

Смагин Михаил Алексеевич - аспирант химического факультета, Воронежский государственный университет, Воронеж
E.M. Akberova; FSBEE HPE VSU. No 2012617310 29.08.2012; registered 26.10.2012. $2 \mathrm{p}$.

31.Taylor J. An introduction to error analysis. California, USA: University Science Books, 1982. $327 \mathrm{p}$.

32. Vasil'eva V. I., Zhil'tsova A. V., Akberova E. M., Fataeva A. I. Condensed Matter and Interphases, 2014, Vol. 16, No. 3, pp. 257-261.

33. Melnikov S., Loza S., Sharafan M., Zabolotskiy V., Separ. Purif. Technol., 2015, Vol. 157, pp. 179-191. DOI: 10.1016/j.seppur. 2015.11.025

34.Svoboda M., Slouka Z., Schrott W., Šnita D., Microelectronic Engineering, 2009, Vol. 86, pp. 1371-1374. DOI: 10.1016/j.mee.2009. 01.019

Akberova Elmara M. - PhD (Chem.), a leading engineer of the Department of Analytical Chemistry, Voronezh State University, Voronezh, e-mail: elmara09@inbox.ru

Vasil'eva Vera I. - Dr. Sci. (Chem.), a professor of the Department of Analytical Chemistry, Voronezh State University, Voronezh, e-mail: viv155@mail.ru

Kostylev Denis V. - a student of the Chemical Faculty, Voronezh State University, Voronezh

Smagin Mikhail A. - a post-graduate student of the Chemical Faculty, Voronezh State University, Voronezh 